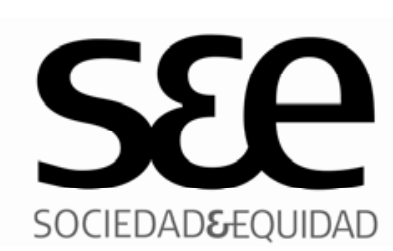

\title{
EDITORIAL:
}

\section{Cuerpos Intervenidos}

\author{
Intervened Bodies
}

Nombre:

Filiación:

País:

Correo:

\author{
Dra. Kemy Oyarzún ( $\left.{ }^{1}\right)$ \\ Universidad de Chile \\ Chile \\ koyarzun@uchile.cl
}

\section{CUERPOS INTERVENDOS}

"Ios conozco a través de sus miradas, sus gestos, sus palabras, en resumen a través de su cuerpo"

Merleau Ponty

Dice J osé Ñancumil de la Isla de Huapi que el silencio le silba "dentro de los huesos". Mientras una temporera insiste que siente que "no tiene vida", para Diamela Eltit, "Ias palabras se escriben sobre los cuerpos", en tanto que según Merleau-Ponty, el cuerpo propio está en el mundo "como el corazón en el organismo", convirtiendo la vida en espectáculo visible y formando con él un sistema-sistema que, diremos, es político a partir del particular engarce que registra entre cuerpo y discurso.

¿Dónde empieza el cuerpo y dónde el lenguaje? ¿Cómo, bajo qué registros se establecen sus fronteras? ¿Cuáles son las operaciones y agenciamientos del poder sobre ambos? El trasfondo de una creciente inquietud sobre el cuerpo parece venir vinculado a la antigua relación entre bíos y zoé, entre vida humana y vida-especie, aunque también remite a los tránsitos entre soma y sema, inscripciones del cuerpo en el mundo y en las palabras. Sin embargo, creo que esa inquietud se resitúa en la crisis contemporánea de representación, la cual desnuda no solo el binarismo, sino la propia lógica sistémica y política, que lo ensambla.

\footnotetext{
${ }^{1}$ Doctora en Filosofía con Mención en Literatura Latinoamericana, Universidad de California, Irvine.Académica e Investigadora de la Facultad de Filosofía y Humanidades. Directora Subprograma Domeyko "Sujetos y Actores Sociales". Investigadora Programa Domeyko Sociedad y Equidad.
} 


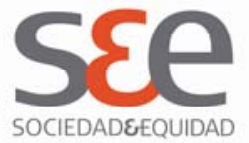

Mientras para J osefina Ludmer el lenguaje es directamente político, Julia Kristeva insiste que el lenguaje es inmediatamente pulsional, acentuando esta última de ese modo que su interés fundamenal no va solo orientado hacia el "referente" al que apunta todo acto de habla, sino a un continuum lengua-vida, porque la vida no estaría desplazada solo a ese otro lugar. Más bien, es a la pulsión inmediatamente copresente en la escritura que Kristeva dedica su reflexión, al ser ésta concebida a su vez como producción deseante. Con ello, la crítica búlgara implosiona el binarismo que ha planteado la lógica excluyente en la proposición bi unívoca: "o el lenguaje 0 la vida", "o el cuerpo o la imagen".

El largo trayecto de oposiciones binarias que dan lugar a esa interrogante desemboca para mí en la encrucijada de relatos referenciales contemporáneos suscitados particularmente a partir de experiencias de terrorismo de Estado y de fragilización corporal en el caso de vivencias laborales en la postdictadura chilena. Esos relatos corporeizados son los que hemos reunido aquí.

Anatomopolítica: escrutar a los sujetos, sus gestos y cuerpos, sus miembros, su interioridad. Producir cuerpos dóciles y fragmentados. La disciplina como instrumento de control del cuerpo social va penetrando hasta sus átomos a los sujetos singulares y a las identidades performáticas. Entonces, vigilancia, control, intensificación del rendimiento, multiplicación de capacidades, emplazamiento y utilidad constituyen verdaderas economías políticas corporales. El poder funciona, se ejercita a través de una organización reticular: corte en el ojo, cámara de fichaje, travelling, intensidad de la mirada. En última instancia, voyerismo se conecta con panóptico.

El concepto de biopoder ha sacudido los límites clásicos de la vida y del poder, del cuerpo y la ficción potenciando engarces radicales de lo estético con la existencia desnuda y política, continuum entre formas estéticas y formas vivientes, entre sema y soma, entre la cuestión ética del sujeto de derecho y el problema del suj eto del lenguaje.

Poner a Agamben a dialogar con Foucault respecto de las repercusiones del concepto liminar de biopolítica se convierte así en un punto de partida para esta discusión. Desde 1989, la labor teórica de Agamben alterna entre la literatura y la teoría política. Recordemos que para él la "nuda vida" refiere al resto humano que queda al ser el sujeto despojado del derecho, porque es ésa la vida que ha sido politizable desde los orígenes--vida anexada a la Ley, al Soberano-a nuestros días (vida-muerte del capital). Luego, ese "desecho de sujeto" se extiende como concepto político a una población civil entera en el caso de los estados de excepción, sobre todo si se trata de luchas neocoloniales o de hiper capitalismo. 


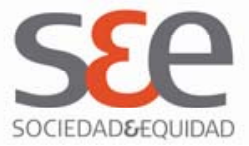

Debo decir que aquí la relación soma y sema me interesa menos como problema ontológico que como problema antropológico y político. Para disidentes y parias, mujeres y locos (as), la nuda vida que Agamben ubica en el descampado del derecho entre la casa y la ciudad no es exactamente el "gran encierro" del que hablaba Foucault. La prisión y el manicomio no agencian la nuda vida del mismo modo que el campo de concentración, territorio de excepción por excelencia. Veo que la inquietud por el cuerpo es signo de diferencia y que esa diferencia es política. El cuerpo no tiene "grado cero"; es siempre situado y sitiado en condiciones concretas, sociales, históricas y por ello, diferentes. Hoy, la nuda vida es despojo de una cierta manera de organizar el mundo, la represión y el capital. El panorama se complica si tenemos en cuenta que para las mujeres, ese descampado ha sido frecuentemente la propia casa, madriguera de desamparo y violencia.

Los cuerpos y la sexualidad son directamente tatuados por relaciones de poder. Sin embargo, sorprende que el diálogo de Foucault con la epistemología feminista sea casi nulo. Después de todo, Donna Haraway sacudió los cimientos del binarismo naturaleza/cultura en la ciencia neopositivista relevando hasta qué punto el logos andro y antropocéntrico reinventa interesadamente las fronteras de "lo natural". Ello es así no solo respecto a marginales del humano (trabajadores flexibilizados, mujeres golpeadas, Mapuche desterritorializados, jóvenes criminalizados), sino en relación a los animales -aquellos primeros artefactos clones de las economías del saber/ poder.

Es interesante entablar diálogos oblicuos entre lo biopolítico, las feministas de la diferencia (italianas como Braidotti) y los "feminismos materialistas" de Fraser, Nicholson y Haraway. Los estudios de esta última sitúan lo biopolítico entre lo natural y lo humano, haciendo visible una serie de tráficos tecno-imaginarios. No se trata solo de constructivismo (bíos y zoé pasan por la grilla del discurso y la historia), sino de un constructivismo inmediatamente político.

La distinción entre biopoder y biopolítica se hace imprescindible. En el mismo momento en que "hacer morir y dejar vivir" se convierte en "hacer vivir y dejar morir", Foucault sitúa liminarmente lo biopolítico. Ese "momento" designa el cambio estatal y económico entre absolutismo y estrategias burguesas. Por ello la 'biopolítica' refiere a lo que hace entrar a la vida y sus mecanismos en el dominio de los cálculos explícitos y convierte al poder-saber en un agente de transformación de la vida humana. Foucault acuña el uso del término distinguiendo dos registros: la anatomía política de los cuerpos individuales entendidos como fuerzas productivas, y el control regulador de la reproducción humana en el nivel demográfico, que se desarrolla como biopolítica de los pueblos.

Si el biopoder ha sido fundamental para la expansión del capitalismo al crear dispositivos para la inserción controlada de los cuerpos en el aparato de producción a 


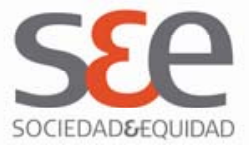

partir de un ajuste de los fenómenos de población a los procesos económicos, en el plano del laboral la biopolítica permite resignificar a la letra la noción de «fuerza de trabajo». Virno insiste: "El origen no mitológico de aquel dispositivo de saberes y poderes que Foucault Ilama biopolítica debe rastrearse, sin dudas, en el modo de ser de la fuerza de trabajo". Dialéctica del tiempo de vida y del tiempo de muerte, dirá Marx al dilucidar el desgaste de vida involucrado en la producción de la mercancía, aquí donde el trabajo es concebido, para Godelier, en tanto "producción de la sociedad", "producción social del vivir" o sencillamente, como "producción del vivir". Así adquieren renovados relieves el deseo productivo, la autopoiesis, la fuerza y la energía pulsional (dynamis).

En la medida en que la vitalidad sea expropiada por el capital, Marx dirá que el tiempo de vida se transformará en tiempo de muerte, tiempo vivo objetificado en un producto que se erige hostilmente contra el sujeto que lo elaboró. Desde esa perspectiva ¿no será biopolítica aquella vieja división sexual del trabajo, coincidente con la división social de los sexos, que asigna para el tiempo femenino un quehacer "reproductivo", desvalorizado y devaluado en tanto "cuidado de otros" ? Aquí donde el tiempo masculino queda exclusivamente vinculado al trabajo "productivo" y donde "capitalismo y patriarcado se reproducen mutuamente", ¿no sería productivo insistir que el propio patriarcado no es más que uno de los más tempranos pliegues del biopoder?

Pareciera un contrasentido encarnar la biopolítica en estos "lejanos territorios", aquí donde las naciones aun se esparcen en mapas concretos y locales demasiado distantes de la supuesta aldea global democratizada. Al menos en Chile, aun se perfila una democracia temerosa de las constituyentes, concebida desde la exclusión y de espaldas a los grandes conjuntos, aquí donde el poder del Estado tiene la capacidad de fijar los límites de la vida digna, la vida indigna y la no vida, en donde gobernar se confunde aun con criminalizar, y, por consiguiente, de fijar indeterminadas y rígidas fronteras al interior de las antiguas Naciones-Estado. Pero también se trafican los límites entre ciudadanía y no ciudadanía, entre el ser con derechos y el ser que no los detenta. Democracia al descampado es este, en el que el imaginario en blanco de la excepción es aun paradigma político imaginable.

Los textos que se incorporan a este número de Sociedad y Equidad resignifican el biopoder en el Chile contemporáneo. Nuestra convocatoria insistía que "la primera conquista del sujeto es la del propio cuerpo, territorio simbólico y material de disputas por el control de deseos y afectos; producción de la vida y de lo viviente". En estos artículos hablan los cuerpos. Para ello, se los incardina y sitúa, se los hace carne en el lenguaje y en las plazas públicas. 


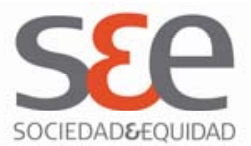

\section{Referencias Bibliográficas}

Agamben, Giorgio (1998). Homo Sacer. El poder soberano y la nuda vida. Valencia: Pre-Textos p. 117-118.

Butler, J udith (1999). El género en disputa. Buenos Aires: Paidós.

Foucault, M. (1977). Historia de la sexualidad. La voluntad de saber. Volumen I, Madrid: Siglo XXI, p. 173.

Foucault, M. (1992). Genealogía del racismo, Madrid: La Piqueta, p. 247.

Foucault, M. (1991). Las redes de poder. Buenos Aires: Ed. Almagesto, p. 2

Foucault, M. (2001). Defender la sociedad. Curso en el College de France (19751976), México: Fondo de Cultura Económica, pp. 232-233

Fraser, Nancy y Linda Nicholson (1988). "Social Criticism without Philosophy: An Encounter between Feminism and PostModernism", en Ross, Andrew, ed., Universal Abandon?, The Politics of Postmodernism, Minneapolis: University of Minnesata Press. Kristeva, J ulia (1988). El lenguaje, ese desconocido. Madrid: Fundamentos.

Marx, Karl (1975). “Leter to A. Ruge, Sept, 1843" en Early Writings, tr. Rodney Lovingstone y Gregos Benton, NY Vintage, 209.

Virno, Paolo (2003). Gramática de la multitud. Madrid: Traficantes de sueños. 